\title{
Вызовы современному русскому литературному языку
}

\section{Challenges for the modern Russian literary language}

\begin{abstract}
The article is devoted to the study of some active processes affecting the system of the modern Russian language. The result of the study is the identification of factors that negatively affect the dynamics of the Russian language, which are presented in socio-political and linguistic aspects. The socio-political reasons are caused by the active reduction of the Russian-language information space in the near and far abroad area under the influence of the collapse of the Soviet Union. Unsuccessful phenomena in the current state of the Russian language consist in the intentional violation of the language norms in the Internet space, the substitution of normative vocabulary for meaningfully and stylistically belittled expressions of rural life, the clogging of the Russian literary language with words and verbal turns of slang origin, the dissemination of obscene vocabulary, the saturation of the language with words and expressions of foreign origin, and the unjustified euphemization of speech, leading to the erosion of the meaning of words. The general conclusion is the need for the serious efforts of the whole society against the simplification and the purity of the Russian literary language.
\end{abstract}

Keywords: Russian, language norm, loan-word, vocabulary, slang

Владимир Медведев, Российский университет транспорта, Москва - Россия, medvedev-mail@ bk.ru, ORCID ID: https://orcid.org/0000-0001-7587-5221

На современном этапе общественного развития русский язык, этот уникальный фактор национального самосознания, подвергается достаточно серьезным испытаниям, представляющим угрозу его самобытности, что вызывает оправданную тревогу не только у филологов, но и у представителей других областей знания. В многочисленных выступлениях и публикациях, посвященных данной теме, рассматриваются, как правило, отдельные аспекты сложившейся языковой ситуации, но отсутствуют работы, затрагивающие проблемные моменты развития современного русского языка в их совокупности.

В данной работе отмечены наиболее значимые, с нашей точки зрения, факторы, влияющие отрицательно на динамику развития русского языка, которые могут быть представлены в двух аспектах: социально-политиче- 
ском и лингвистическом. Кроме того, настоящее исследование, построенное на анализе литературных и публицистических источников, в какой-то мере дополняет имеющиеся по затронутым вопросам статьи, в которых рассмотрение языковой ситуации осуществляется преимущественно по выборке устных речевых фактов. Такой подход позволяет с большим основанием свидетельствовать о глубине проникновения неблагоприятных явлений в основы русского литературного языка.

\section{1. Социально-политические причины, вызвавшие кардинальные изменения в русскоязычном языковом пространстве}

\section{1. Активное сокращение русскоязычного информационного пространства в ближнем и дальнем зарубежье}

Распад СССР и, как результат, ослабление прежнего экономического, технологического и геополитического влияния России на постсоветском пространстве и в мире в целом отразились и на положении русского языка в ближнем и дальнем зарубежье. В общей сложности за последние 25 лет количество владеющих русским языком сократилось с 350 до 300 млн. человек ${ }^{1}$.

К настоящему времени на территории 14 бывших республик СССР русским языком активно владеют, по оценкам экспертов, лишь 63,6 миллиона человек; еще 39,5 миллиона человек владеют им пассивно (в той или иной мере понимают его, но не используют как средство коммуникации и постепенно утрачивают языковые навыки), а почти 38 миллионов уже не владеют русским языком (табл. 1).

Таблица 1. Численность населения, в той или иной мере владеющего русским языком, в странах СНГ и Балтии в 2004 году (тысяч человек) (Aref'ev, электронный ресурс)

\begin{tabular}{|l|l|c|c|c|c|c|}
\hline \multicolumn{1}{|c|}{ Страны } & $\begin{array}{c}\text { Статус русского } \\
\text { языка в стране } \\
\text { Общая } \\
\text { нослен- } \\
\text { населения }\end{array}$ & $\begin{array}{c}\text { Число } \\
\text { считающих } \\
\text { русский } \\
\text { язык род- } \\
\text { ным }\end{array}$ & $\begin{array}{c}\text { Число } \\
\text { активно } \\
\text { владеющих } \\
\text { русским } \\
\text { языком }\end{array}$ & $\begin{array}{c}\text { Число } \\
\text { пассивно } \\
\text { владеющих } \\
\text { русским } \\
\text { языком }\end{array}$ & $\begin{array}{c}\text { Число не } \\
\text { вугеюкими } \\
\text { языком }\end{array}$ \\
\hline $\begin{array}{l}\text { Азербайд- } \\
\text { жан }\end{array}$ & иностранный & 8200 & 250 & 2000 & 3500 & 2700 \\
\hline Армения & иностранный & 3200 & 15 & 1000 & 1200 & 1000 \\
\hline
\end{tabular}

${ }^{1}$ Сужение русскоязычного информационного пространства известный экономист Константин Колин считает необходимым рассматривать в ракурсе „объекта национальной безопасности" (Kolin, электронный ресурс) 


\begin{tabular}{|l|l|c|r|r|r|r|}
\hline Белоруссия & $\begin{array}{l}\text { государствен- } \\
\text { ный }\end{array}$ & 10200 & 3243 & 8000 & 2000 & 200 \\
\hline Грузия & иностранный & 4500 & 130 & 1700 & 1000 & 1800 \\
\hline Казахстан & официальный & 15100 & 4200 & 10000 & 2300 & 2800 \\
\hline Киргизия & официальный & 5000 & 600 & 1500 & 2000 & 1500 \\
\hline Латвия & иностранный & 2300 & 960 & 1300 & 700 & 300 \\
\hline Литва & иностранный & 3400 & 250 & 500 & 1400 & 500 \\
\hline Молдавия & $\begin{array}{l}\text { язык межна- } \\
\text { ционального } \\
\text { общения }\end{array}$ & 3400 & 450 & 1900 & 1000 & 500 \\
\hline Таджикистан & $\begin{array}{l}\text { язык межна- } \\
\text { ционального } \\
\text { общения }\end{array}$ & 6300 & 90 & 1000 & 2000 & 3300 \\
\hline Туркмения & $\begin{array}{l}\text { язык межнацио- } \\
\text { нального обще- } \\
\text { ния/фактически } \\
\text { иностранный }\end{array}$ & 4800 & 150 & 100 & 900 & 3800 \\
\hline Узбекистан & $\begin{array}{l}\text { язык межна- } \\
\text { ционального } \\
\text { общения }\end{array}$ & 25000 & 1200 & 5000 & 10000 & 10000 \\
\hline Украина & $\begin{array}{l}\text { язык нацмень- } \\
\text { шинства }\end{array}$ & 48000 & 14400 & 29000 & 11000 & 8000 \\
\hline Эстония & иностранный & 1300 & 470 & 500 & 500 & 300 \\
\hline Итого & 140700 & 26408 & 63600 & 39500 & 37700 \\
\hline
\end{tabular}

Особенно быстро сокращается число носителей русского языка среди молодого поколения. Так, в Литве русским языком владеют сегодня в среднем $60 \%$ населения, в том числе среди лиц среднего и старшего возраста $80 \%$, а среди детей и подростков в возрасте до 15 лет - всего 17\%. Аналогичная картина складывается в западных областях Украины. В Молдавии, Азербайджане, Армении, Грузии, Туркмении, Узбекистане, Эстонии и некоторых других странах происходит переориентация молодежи на знание европейских языков. Количество этнических русских, как основных носителей русского языка и культуры, оказавшихся за пределами своей исторической Родины, сократилось за последние годы с 25-30 миллионов человек до 17 миллионов человек - не только в результате выезда в другие страны, но и вследствие депопуляции, а также смены национальной идентичности. И есть основания полагать, что этот процесс при неизменности влияющих на него факторов в ближайшие годы будет усиливаться.

Важнейшим индикатором положения русского языка на постсоветском пространстве является количество образовательных учреждений с преподаванием на русском языке и число обучающихся в них школь- 
ников. По сравнению с советским периодом количество средних школ с обучением на русском языке уменьшилось в странах СНГ и Балтии (за исключением Белоруссии) в среднем в 2-3 раза (а в отдельных странах в 10 и более раз).

В дальнем зарубежье отчасти преодолен этап снижения интереса к изучению русского языка, отмеченный в 90-х годах прошлого столетия. В Болгарии и Польше, например, в плане предпочтений по изучению иностранных языков русский переместился соответственно с 14-го и 16-го на второе место после английского языка. Подобная тенденция прослеживается в Словакии и Чехии (Sibilev). Тем не менее, несмотря на то, что в настоящее время русский язык сравнялся с испанским по популярности в Евросоюзе, а в США по-русски говорят 4,5 млн. человек и действуют 3 тыс. школ с русским языком обучения (Sibilev), представляется маловероятным восстановление в ближайшем будущем прежнего количества носителей русского языка.

Немалый интерес представляет собой ситуация с русским языком и в национальных регионах РФ, в которых за русским языком и языком титульной нации закреплен в равной степени статус государственного языка. На этом основании нередко на изучение русского языка выделяется такое же количество часов, как и на изучение языка титульной нации региона в рамках сетки часов, предусмотренных программой на изучение русского языка. Нетрудно представить, что добровольно-принудительное вовлечение русскоязычных учащихся в упомянутый национально-ориентированный образовательный процесс отрицательно влияет на уровень знания школьниками государственного языка Российской Федерации. Заявление Президента России Владимира Путина на заседании Совета по межнациональным отношениям в Йошкар-Оле в июле 2017 года о недопустимости принудительного изучения неродного языка и снижения уровня и времени преподавания русского не ослабило страстей в дискуссиях по данной проблеме (Aref'ev, электронный pecypc).

Несмотря на отсутствие прямого закрепления в Конституции права автономных округов и автономных областей устанавливать собственные государственные языки, некоторые субъекты Российской Федерации определяют официальный статус языков собственными уставами и законами. И так же, как в случае с национальными республиками, изучение этнического языка осуществляется в этих национально-территориальных образованиях за счет объема часов русского языка.

Данные обстоятельства не могут не сказываться на качественной стороне владения русским языком лиц, проживающих в различных регионах Российской Федерации. 


\section{2. Аспекты лингвистического характера, свидетельствующие о неблагополучном состоянии русского языка}

Тревожная ситуация, сложившаяся с государственным языком настолько очевидна, что по данным опроса общественного мнения, проведенного в 2019 году ВЦИОМ, две трети респондентов считают, что необходимо бороться за чистоту русского языка всеми доступными средствами (Pressvypusk WCIOM). Какие же изменения, происходящие в современном русском языке, могли встревожить неравнодушных к его судьбам россиян? Рассмотрим коротко наиболее значимые из них.

\section{1. Нарушение языковой нормы}

Особенно резко отклонения от принятой языковой нормы проявляются в интернет-пространстве, где пренебрежение лексико-грамматическими правилами стало общим местом (Voznesenskaâ, Popova). В последние годы среди определенных групп молодежи стало модным говорить и писать с ошибками, сознательно искажая слова родного языка, что наиболее резко проявляется в компьютерной речи. Среди любителей „новой орфографии” популярны, например, выражения ацикий сотона, превед кросавчег, превед солни, пасиб, кстате, будющее и др.

\section{2. Огрубление литературного языка за счет подмены нормативной} лексики содержательно и стилистически приниженными выражениями сельского быта

Современный период развития российского общества знаменателен слиянием города с деревней за счет бурного переселения сельчан в поисках работы в крупные города, что, несомненно, сказывается и на проникновении лексики сельского быта в речь горожан. У образованного человека вызывает недоумение использование в речи совершенно неуместных выражений, характерных для сельского обихода: окучивать вопрос, врезать по самые nомидоры, naхать в значении 'работать', молотить - в значении 'изби-вать; болтать’. Ср.: „Сейчас он Спире врежет! - подумал Кирилл. - По самые помидоры!" (Romanov).

\section{3. Засорение русского языка словами и словесными оборотами жаргонного происхождения}

По поводу „главной приметы русского литературного языка конца XX начала XXI века" (Brusenskaâ) - использования в русской речи слов и обо- 
ротов жаргонного характера лингвисты уже давно бьют тревогу. Все чаще в языке встречаются вульгаризмы и слова ненормативной лексики, вызванные появлением целого класса деловых людей с криминальным прошлым, пополнивших язык соответствующими лексическими единицами. Прямые заимствования из лексикона преступного мира (наезд, беспредел, мочить, крыша, бабки, тусовка и проч.) стали едва ли не нормативными в речевом употреблении. В результате, светский раут вполне может быть назван в СМИ тусовкой, под которой в криминальной среде понимается компания проституток, бомжей (Baldaev 250).

Интересно, что в начале 90-х годов, когда только наметился процесс криминализации общества, авторы литературных произведений из робости заключали подобные слова в кавычки, например, „Людей «опускают» по приговору воров за разные грехи: стукачество, неуплату карточного долга, неподчинение «авторитету», за то, что на следствии «сдал» подельников, что имеет родственников в правоохранительных органах [...]" (Trud 27.11.1991). Спустя четверть века криминальная лексика потеснила нормативный лексикон и завоевала свое место в социальной жизни, став общедоступной пониманию и, соответственно, употреблению. Поэтому современные авторы, используя выражения уголовной среды, уже к кавычкам не прибегают. Вот образчик выдержек из газетных статей: „Что за кипеж в Виноградове [...]” (Komsomol'skaâ pravda 15.03.2019); „Анну Снаткину бывший ухажер кинул на 3000000 рублей” (Komsomol’ skâ̂ pravda 25.08.2011); „Что за дебилы! Мочить уличных гонщиков во всем” (Komsomol'skâ̂ pravda 02.07.2011); „Прямо ментовский беспредел какой-то!” (Komsomol'skaâ pravda 26.08.2011).

Подобную лексику поэт Асар Эппель образно и точно назвал „тюрьмизмами”, а происходящий сегодня процесс безоглядного опошления русского языка - „привокзализацией”.

\section{4. Распространение обсценной лексики}

Этические требования к использованию лексических элементов снижаются, в результате чего у многих авторов появляется соблазн переносить их в той или иной форме на страницы художественных произведений. Писатель Алексей Слаповский в романе Денег нет использует нецензурные слова, обозначая их начальными буквами. Виктор Пелевин в Священной книге оборотня прибегает к подобному же способу, присвоив ненароком главной героине редкое восточное имя А Хули. Отсюда следует такой пассаж: „Да, окрашивает мою жизнь в угрюмые тона, и какой-нибудь из внутренних голосов всегда готов спросить - а х [...] ты ждала от этой жизни, А Хули?” (Pelevin 15). 
Журналист Сергей Пархоменко процитировал на радиостанции „Эхо Москвы” (24.05.2019) в своей интерпретации известное высказывание американского президента Линдона Джонсона, что более предпочтительной представляется ситуация, когда враг справляет малую нужду из палатки наружу, чем, находясь за ее пределами, внутрь палатки ${ }^{2}$, не посчитав нужным, заменить в переводе обсценное слово его эвфемизмом.

\section{3. Вестернизация русского языка}

Вестернизация русского языка - это процесс засорения русского языка терминами и словесными оборотами иностранного происхождения.

Большая часть заимствований обусловлена обновлением материального мира и представляет собой обычный процесс социального и языкового взаимодействия. Так, слово хостел, вопреки наличию русского эквивалента гостинииа, уверенно закрепилось в современном российском туристическом бизнесе благодаря появлению в январе 2015 официального определения этих объектов гостевого размещения и регламентирующих их работу ГОСТов, в соответствии с которыми хостелы не могли быть отнесены к гостиницам в привычном понимании.

В сферу данной профессиональной принадлежности входит и новомодный термин отельер, означающий директора гостиницы. Ср.: „В результате в Москве может закрыться 40\% ныне существующих хостелов, а в Петербурге - 80\%, предупреждают отельеры” (RBK 06.03.2019: 13). „Больше всего хостелов - в Москве и Петербурге, оценивают сами отельеры" ( $R B K$ 06.03.2019: 13).

Положительным явлением может считаться обогащение языка за счет новых интересных слов или устойчивых словосочетаний, как, например, появление немецкой кальки Chemie entsteht (stimmt) - „возникает химия” или попросту химия “симпатия'. Ср.: „Никакой личной «химии»” (Rossijskâิ gazeta, $\mathrm{nr}$ 92, 28.04.2018: 6); „[...] химия в кадре возникает исключительно между этими двумя [...]" (Kommersant weekend 10.06.2016: 27).

Впрочем, калькированные иностранные слова и выражения должны вписываться в сложившуюся языковую норму, на что обращают внимание авторы монографии Константы и переменные в русской языковой картине мира, подробно анализируя лексему вызов в нехарактерном для этого слова значении, соответствующем английскому challenge (Zaliznâk et al. 550).

${ }^{2}$ Cp.: ,[...] good $[\ldots]$ to have them inside the tent peeing out, than outside the tent peeing in” (Haber, электронный ресурс). 
Настораживает в процессе языковых изменений лишь факт пополнения лексики за счет иностранных слов с бесцветным содержанием, для которых в русском языке уже имеются устойчивые аналоги. Ср.: „На записи видно, как она пытается справиться с крупной дрожью во всем теле. [...] Канцлер объяснила причину первого тремора (дрожи) обезвоживанием из-за долгого нахождения на солнце. [...] Медицинский корреспондент газеты The Times доктор Марк Портер считает, что причиной состояния госпожи Меркель может быть неврологическое расстройство - эссенциальный тремор (Komsomol'skaâ pravda 04.07.2019: 2).

Неоправданной можно считать также беспричинную замену одного иностранного слова, уже давно прижившегося в языке, на другое. Ср.: инструмент - драйвер, приток энергии - драйв, преимущество - бонус. Ср.: „Основным драйвером роста цен [...] стало значительное повышение ценовой конъюнктуры нефтяного рынка [...]” (RBK 08.07.2019: 8); „Во второй встрече ЦСКА победил с разницей в пять очков только благодаря поймавшему бешеный драйв Серхио Родригесу” (Kommersant 26.04.2018: 12); „[...] у команды был бонус в виде фактора своей площадки [...]" (Kommersant 26.04.2018: 12).

Избыточность новых слов в сложившейся системе языка настолько очевидна, что процесс их освоения начинается с перевода на русский язык. Ср.: „В [...] аэрокосмической промышленности важна не только сама обработка, но и так называемое упрочение поверхности, наклеп - shot-peening" ( $R B K$ 08.07.2019: 7); „[...] Григорий Асмолов назвал принцип работы карты помощи термином «краудсорсинг» - использование «ресурса толпы», сетевого общества для решения каких-либо задач" (Moskovskij komsomolec 23.01.2012: 3); „Он ночной гонщик. Стритрейсер” (от street racing - 'уличные гонки') (Komsomol'skaâ pravda 02.07.2011: 6).

К тому же многие заимствования некорректно переведены и истолкованы. Например, нередко можно услышать выражение провести маркетинг, под которым ошибочно подразумевается изучение потребности рынка, в то время как маркетинг означает организацию производства и сбыта продукции.

Бороться с опустошающими русский язык заимствованиями можно и нужно, например, путем привлечения общественного мнения. Так, писатель Евгений Водолазкин в день рождения Пушкина, 6 июня 2018 г., предложил неравнодушной к языку общественности подумать над заменой варваризма ресепшн более благозвучным словом. Из 54 присланных на конкурс слов жюри вначале выбрало тройку финалистов: рещепщия, привечальня и гостевая, отдав, в конечном счете, предпочтение слову гостевая (Vodolazkin, электронный ресурс). 


\section{4. Ослабление контроля при осуществлении редакторской правки}

Не редкость присутствие в тексте орфографических ошибок, допущенных безответственными редакторами. Ср.: „Любое локальное перепроизводство [...] может привезти к резкому скачку цены” (RBK 08.06.2019: 8).

Отмечаются ляпы лексического характера. Ср.: „Семья оказалась на уровне, и ребенка отпустили в художники” (Rossijskấ gazeta 02.07.2011: 5).

Нарушение стилистической отнесенности языковых единиц, как в нижеследующем примере, где в серьезной аналитической статье используется просторечный элемент, ср.: „Рынок гречневой крупы фактически изолирован от всего мира, потому как гречку едят только в России" (RBK 08.06.2019: 8).

Не отличаются присутствием изысканного стилистического вкуса и попытки использования некоторых неологизмов, намытых потоком новой жизни: сбайкалить 'украсть' (после „Байкал Финанс Групп”), кержакнуться 'опростоволоситься' (после не забитого футболистом Кержаковым гола), перемандаченные (губернаторы) - т. е. получившие от президента мандат на новый срок.

Особое внимание на повседневный язык оказывает императивная реклама, которой русский язык должен быть обязан (отнюдь не признателен) за появление такого неологизма как сникерснуть. Ср.: „Не тормози - сникерсни!”; „Сникерсни, живи со вкусом, оторвись по полной!”. При этом тревогу вызывает не столько словесная неуклюжесть подобных элементов, сколько сопутствующий эффект закрепления императива в сознании определенной модели в качестве жизненной установки и, разумеется, поведения.

И этот далеко не полный список нарушений языковой нормы можно было бы, к сожалению, значительно расширить. Результаты проведенного исследования свидетельствуют о том, что современный русский язык действительно подвержен негативным изменениям, затрагивающим основы языковой нормы. Отклонения от существующей лексической и стилистической нормы русского языка носят массовый характер, проникая из разговорной речи на страницы художественных произведений, в средства массовой информации.

В связи со сказанным выше становится очевидным, что перечисленным языковым процессам необходимо всячески противодействовать. И если исправление последствий геополитических потрясений относится к прерогативе экономистов и политиков, то преодоление угрозы упрощения языка, приводящего к ущербности вербального мышления, является задачей не только языковедов, но и всех неравнодушных членов нашего общества. Суть предпринимаемых действий должна состоять не столько в работе с отдель- 
ным словом, сколько в перемене отношения к языку вообще и, говоря в терминах Дмитрия Сергеевича Лихачева, ратовавшего за „экологию культуры”, в направлении усилий на осуществление мер по экологии языка.

\section{Библиография}

Aref'ev, Aleksandr. Padenie statusa russkogo âzyka na postsovetskom prostranstve. Web. 20.08.2008. http://www.demoscope.ru/weekly/2006/0251/tema01.php.

Baldaev, Dancik S. Slovar' tûremno-lagerno-blatnogo žargona (rečevoj i grafičeskij portret sovetskoj tûr'my). Odincovo, Kraâ Moskvy, 1992.

Brusenskaâ, Lûdmila. „Kriminalizaciâ institucional'nogo diskursa: problema žargonizacii sovremennogo russkogo literaturnogo âzyka". Filosofiâ prava, 3 (64), 2014, s. 84-87.

Haber, Matt. „Daily Show's LBJ 'Piss' Take”. Web. 19.11.2008. https://observer.com/2008/11/ idaily-showis-lbj-piss-take.

Kolin, Konstantin. O roli russkogo âzyka $v$ sohranenii edinogo informacionnogo prostranstva Rossii. Web. 12.11.2019. http://emag.iis.ru/arc/infosoc/emag.nsf/BPA/36b91bb5eaacbbf1c32 $575 \mathrm{c} 20046 \mathrm{c} 176$.

Krylov, Anton. „Tatarstan pytaetsâ vzât' revanš po âzykovomu voprosu ”. Vzglâd. Delovaâ gazeta. Web. 26.04.2018. https://vz.ru/society/2018/4/26/919959.html.

Pelevin, Viktor. Svâsennaâ kniga oborotnâ. Moskva, Eksmo, 2008.

Romanov, Nikolaj. General ot mašinerii. 2017. Web. https://books.google.ru > books.

Sibilev, Viktor. „Sootečestvenniki i položenie russkogo âzyka za rubežom”. Meždunarodnaâ žizn', 12, 2011.

Slapovskij, Aleksej. Deneg net. Moskva, Eksmo, 2005.

Vodolazkin, Evgenij. Ėkologiâ âzyka. Pisatel' Evgenij Vodolazkin - o berežnom otnošenii k rodnoj reči. Web. 13.09.2018. https://iz.ru/786591/evgenii-vodolazkin/ekologiia-iazyka.

Voznesenskaâ, Irina, Tat'âna Popova. „Pravila rečevogo povedeniâ v internet-obŝenii: normativnyj i ètičeskij aspekt”. Mir russkogo slova, 3, 2009, s. 47-59.

Zaliznâk, Anna, Irina Levontina, Aleksej Šmelev. Konstanty i peremennye russkoj âzykovoj kartiny mira. Moskva, Âzyki slavânskih kul'tur, 2012.

\section{Периодические издания}

Kommersant, 26.04.2018.

Kommersant weekend, 10.06.2016.

Komsomol'skâ̂ pravda, 02.07.2011.

Moskovskij komsomolec, 23.01.2012.

Press-vypusk WCIOM, 3897. Web. 06.03.2019. https://wciom.ru.

RBK-Rosbizneskonsalting, 8.06.2019.

Rossijskaâ gazeta, 02.07.2011.

Trud, 27.11.1991. 